\title{
A numerical simulation of static stiffness and strength of circular saw blade
}

\author{
Ondřej Bílek ${ }^{1, *}$, Oldřich Šuba ${ }^{1}$, and Jitka Bad'urová ${ }^{2}$ \\ ${ }^{1}$ Tomas Bata University in Zlín, Department of Production Engineering, Vavrečkova 275, 76001 Zlín, Czechia \\ ${ }^{2}$ Tomas Bata University in Zlín, Department of Physics and Materials Engineering, Vavrečkova 275, 76001 Zlín, Czechia
}

\begin{abstract}
The paper deals with the evaluation of the static stiffness and strength, which are critical parameters affecting the stability of the machining process but also the safety and durability of the wood cutting tools. Circular saw blade models for the purpose of computer numerical simulation were proposed using finite element methods, and verified in earlier research. Deformation response was observed, depending on the input parameters correlating to the saw blade woodworking conditions. The strength of the saw blade was compared with the different clamping methods and different thickness of the circular saw blade. An article gives a disturbing finding how minor change in the quality of the circular saw blade clamping, specifically one degree of misalignment, leads to critical states and probable cause of damage.
\end{abstract}

\section{Introduction}

Machining processes in general and woodworking processes in particular are complex processes with many interacting factors. Wood is, unlike synthetic or artificial materials, inhomogeneous biological material with distinctly different mechanical properties. For understanding the woodworking process is a fundamental to investigate the interaction between the material, the cutting tool and the process parameters [1].

The circular saw blades play an important role in the cutting process. It affects process productivity, cutting stability, and machining accuracy. It must also meet the safety requirements. The operating parameters of the circular saw blade can be summarized as follows:

- The circumferential speed of saw blade affects productivity, surface quality, wear of cutting edges, and to a lesser extent, the size of cutting forces. The optimal circumferential speed is between 30 and $60 \mathrm{~m} / \mathrm{s}$, but circular saw blades for work speed at $100 \mathrm{~m} / \mathrm{s}$ are not the exception [2].

- Feed on the tooth as well as chip thickness, affect productivity, surface quality of workpiece and cutting force. When cutting wood, the theoretical chip thickness is almost the same as the thickness of the cut chips $[3,4]$. - The number of teeth of the sawing tool affects its own productivity, surface quality, and sometimes even feed limitation to the tooth [5].

Another parameter is the thickness of the saw blade. Thin circular saw blades are desirable because they have a smaller kerf and thus lower waste. On the other hand, thin saw tools are less tolerant to variable cutting conditions and is more difficult to maintain.

The knowledge of lateral stiffness contributes to the choice of the appropriate thickness of the circular saw blade. According to GOST 980-80, lateral stiffness should be greater than $40 \mathrm{~N} / \mathrm{mm}$ in rip sawing and greater than $25 \mathrm{~N} / \mathrm{mm}$ in cross-cutting. If values are lower, it is necessary to use guides [6-10].

In this work, von Mises' stress $\sigma$, which is defined as the equivalent tensile stress (reduced stress), is evaluated and used for tough materials such as steel to predict multi-axis stress using the results of simple tensile tests. In this paper, we will consider that as a benchmark for the strength of the circular saw blade, generally used in computer numerical analysis. The object of the analysis is the circular saw blade made of tool steel $75 \mathrm{Cr} 1$ with stellite cutting inserts with two outer expansion slots and two inner slots. For numerical computations of lateral stiffness and strength, the circular saw blade is considered homogeneous properties.

\section{Materials and methods}

The subject of the experiment is the analysis of the lateral stiffness and strength of the actual saw blade, for which has been observed in a few cases destruction during the woodworking process itself. Therefore, for this purpose was a process numerically simulated by the finite element method (FEM). Since this is one of the primary study, a static analysis is presented, using a 3D model for strength analysis in the Catia software and for determining the lateral stiffness of the computer model of the circular saw blade in Cosmos/M Design Star.

The shape and geometry of the model of circular saw blade is shown in Figure 2, is identical to the actual tool provided by the tool manufacturer (Figure 1). The geometric parameters of the circular saw blade and thus the computer model are shown in Table 2.

\footnotetext{
* Corresponding author: bilek@utb.cz
} 


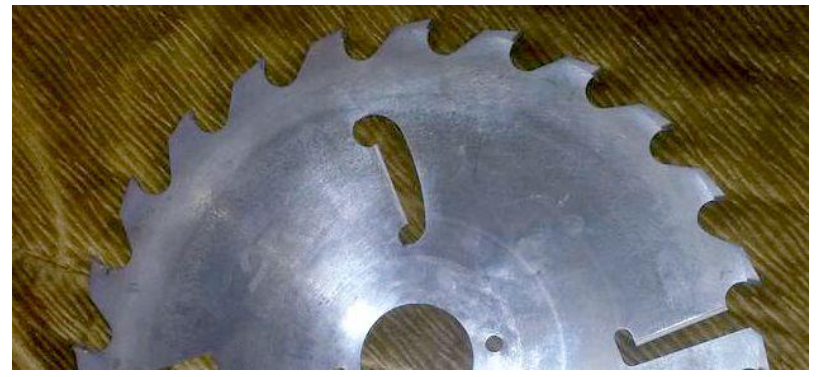

Fig. 1. Existing circular saw blade.

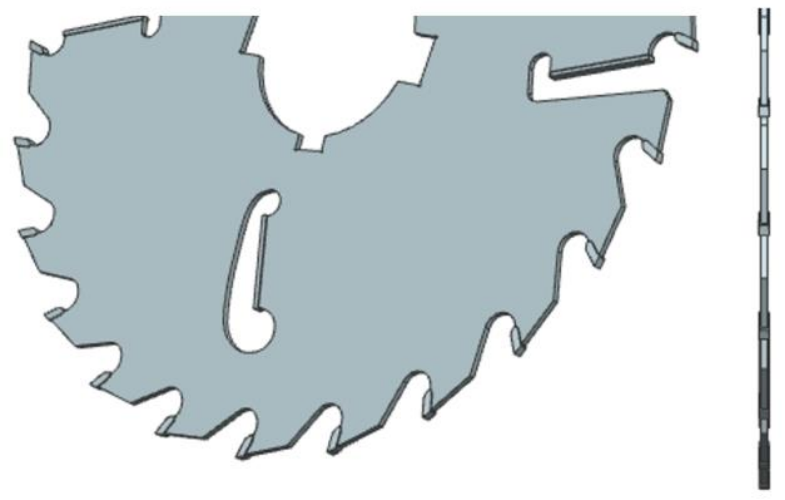

Fig. 2. Computer model.

The material of the saw blade was made of $75 \mathrm{Cr} 1$ tool steel with mechanical properties listed in Tab. 1. The material is considered to be homogeneous even in the area of teeth, although they were saw inserts made of stellite material. This is a simplification for FEM analysis and is considered in the discussion of the results, but it does not affect the results of the experiment.

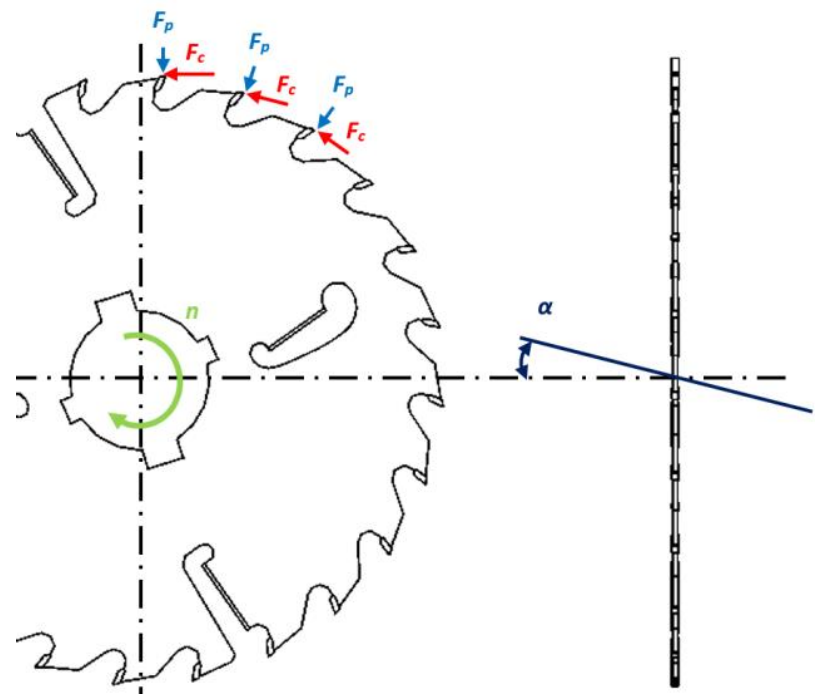

Fig. 3. Principle of load application, direction of circular speed and axis tilt.

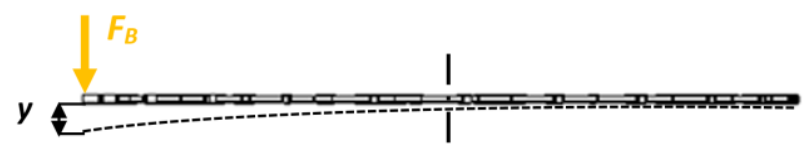

Fig. 4. Loading by lateral force $F_{B}$ and deflection $y$.
For strength analysis, a 3D model of circular saw blade was used, subsequently was loaded with cutting forces to advance toward the real woodworking process. According to the machining theory, the dependence between the force components $F_{c}: F_{p}$ is given by a ratio of $2: 1$. The circular saw blade saw at the same time subjected to centrifugal force due to the rotation of the model as shown as $n$ vector in Figure 3. The effect of the clamping is monitored by the fact that the model is either flanged or on the key. The dependence of the cutting forces and the rotation speed on the total distribution of the von Mises tension in the model was determined together with the displacement. In addition to the strength of the circular saw blade and its critical areas, stiffness for lateral force is determined in individual variants. The experimental input conditions are summarized in Table 3 . The numerical simulations included a clamp inaccuracy, characterized as the clamping aperture of $1^{\circ}$ apart from the axis of rotation.

The loading of the blade by the static lateral force $F_{B}$ at the position shown in Figure 4 results in the deflection, which maximal value $y(\mathrm{~mm})$ was registered. From the ratio and functional expression, it is possible to determine lateral stiffness $C_{B}$, which is of greatest importance for the stability of the cutting process. Mathematical equation of static stiffness is expressed as:

$$
C_{B}=F_{B} / y(\mathrm{~N} / \mathrm{mm}) .
$$

Table 1. Mechanical properties of circular saw blade body.

\begin{tabular}{|c|c|}
\hline Property & Value \\
\hline Density & $7850 \mathrm{~kg} / \mathrm{m} 3$ \\
\hline Poisson number & 0.28 \\
\hline Elastic modulus & $200 \mathrm{GPa}$ \\
\hline Threshold tensile strength $\sigma_{p}$ & $650-880 \mathrm{MPa}$ \\
\hline Yield strength $\sigma_{k}$ & $350-550 \mathrm{MPa}$ \\
\hline Fatique strength & $275 \mathrm{MPa}$ \\
\hline
\end{tabular}

Table 2. Geometrical parameters of circular saw blade.

\begin{tabular}{|c|c|}
\hline Property & Value \\
\hline Outer diameter of circular saw blade & $350 \mathrm{~mm}$ \\
\hline Number of teeth & 24 \\
\hline Inner diameter of clamping hole & $80 \mathrm{~mm}$ \\
\hline Tooth width & $4 \mathrm{~mm}$ \\
\hline Tooth height & $4 \mathrm{~mm}$ \\
\hline Number of radial compensation slots & 2 \\
\hline Number of clearing teeth & 2 \\
\hline Compensating rolling & $0.66 \mathrm{R}$ \\
\hline Side clearance angle & $14^{\circ}$ \\
\hline Side-rake angle & $18^{\circ}$ \\
\hline Side relief angle & $58^{\circ}$ \\
\hline Tooth shape & $\mathrm{FZ}$ \\
\hline
\end{tabular}

Table 3. Summary of input parameters.

\begin{tabular}{|c|c|}
\hline Property & Value \\
\hline Clamping method & Flange, Key \\
\hline Rotation speed $n$ & $3500 \mathrm{rpm}$ \\
\hline Tangential force $F_{c}$ & $110 \mathrm{~N}$ \\
\hline Pasive force $F_{p}$ & $55 \mathrm{~N}$ \\
\hline Axis tilt $\alpha$ & $1^{\circ}$ \\
\hline $\begin{array}{c}\text { Thickness of circular saw } \\
\text { blade body }\end{array}$ & 2.6 and $3.0 \mathrm{~mm}$ \\
\hline
\end{tabular}




\section{Results and discussion}

\subsection{Strength of rotating circular saw blade}

In Figure 5 is the result of a numerical FEM simulation in the case of clamping by the key. The maximum stress according to the scale on the right side of the figure is $450 \mathrm{MPa}$ and these values are close to the key way. This value interferes with range values of the circular saw blade yield strength, and therefore there may be small, yet permanent deformations of the saw blade. However, tool retains a low state of stress overall body, excepting the weak points close to the slots and the flange hole.
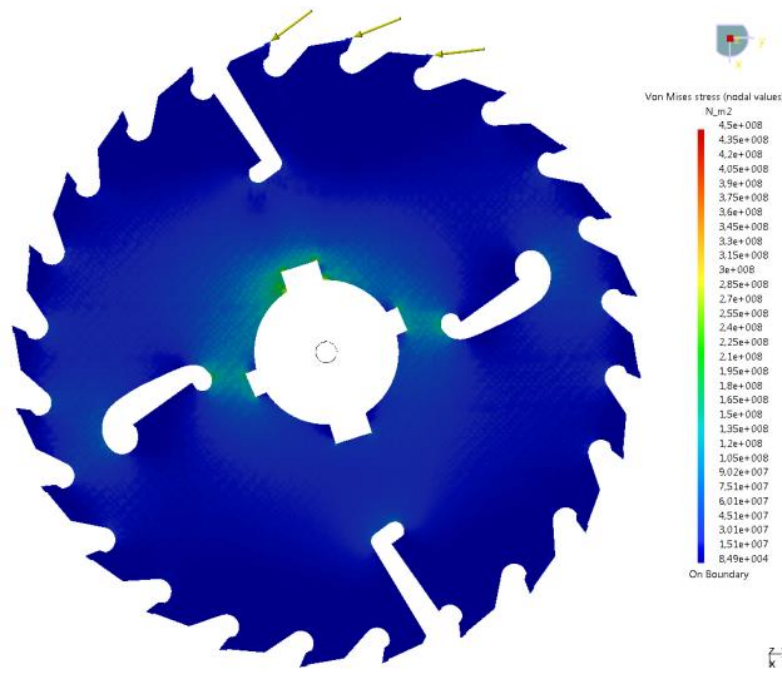

Fig. 5. Von Mises stress for circular saw blade clamped by the key.
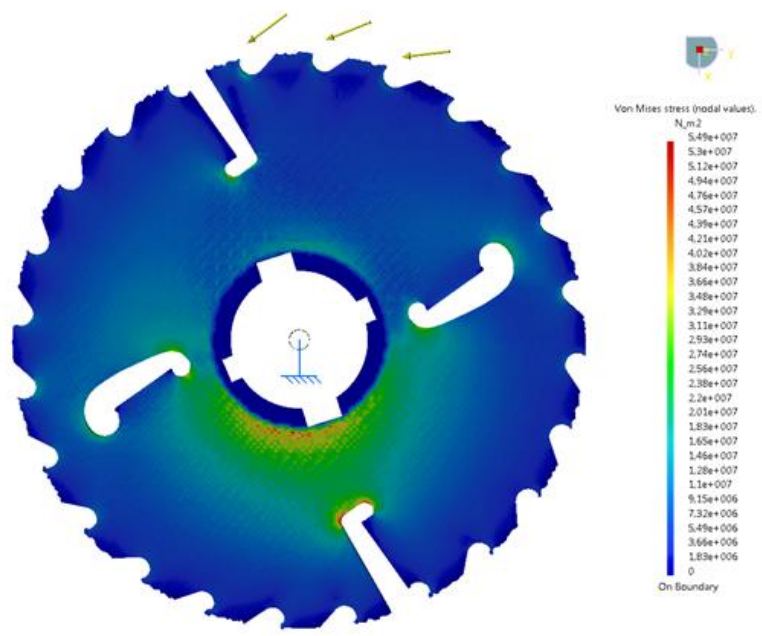

Fig. 6. Von Mises stress for circular saw blade clamped by the flange.

Changing the clamping of the circular saw blade causes a significant change in the strength while maintaining the load and boundary conditions. In Figure 6 is the course of strength as a colour-differentiated von Mises stress. On the model, the peaks of stress on stellite teeth have been filtered since this material has a considerably greater strength than the saw blade body. A maximum stress of $54.9 \mathrm{MPa}$ is achieved at sites opposite to the cutting forces. There is an increased stress concentration in the area of the outer expansion slots and the flange hole. These places could be, under certain conditions, such as guiding the workpiece at a large angle, a place where the tool may break. Yet, in all the observed cases, the strength limit and the yield strength were not exceeded.

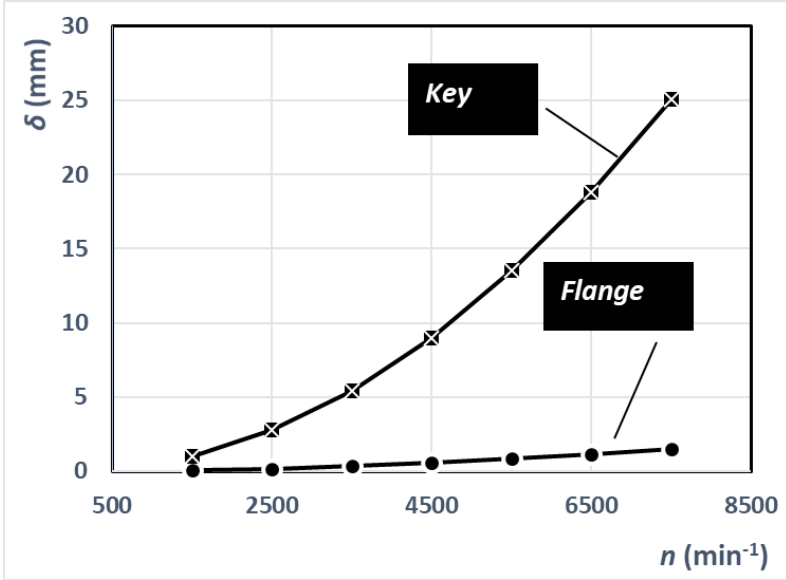

Fig. 7. Maximal radial deformation $\delta$ in circular saw blade depending on the applied force $F_{c}$ and clamping method.

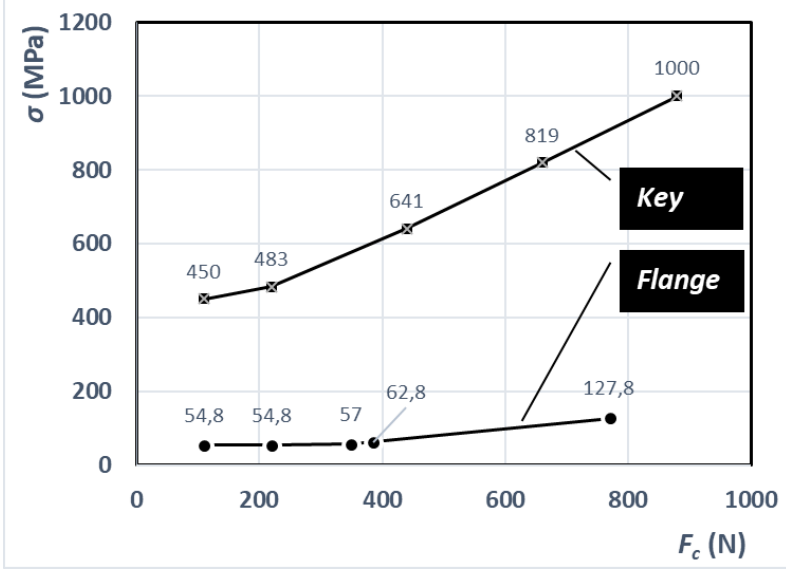

Fig. 8. Maximal stress in circular saw blade depending on the applied force $F_{c}$ and clamping method.

From previously published work [11] it was found that already at $2900 \mathrm{rpm}$ and higher, the yield strength was exceeded and consequently a permanent and irreversible deformation occurs. The deformation velocity and its course in dependence on the rotation speed can be seen in the graph in Figure 7. While the clamping on the flange does not reach the critical states, the clamping over the key above $4100 \mathrm{rpm}$ exceeds the lower threshold of the tensile strength and, in terms of deformations, is beyond safe and stable machining.

The results of the simulation with variable cutting force under constant conditions $(n=$ const. $=3500 \mathrm{rpm})$ are significant because they simulate not only the impact of the cutting process, but can also contribute to prediction behaviour depending on the nature of the cut 
wood (hard, soft). A linear behavioural pattern (Figure 8) between the von Mises stress and the tangential force $F_{c}$ is determined for the case of a key clamp in a mathematical form:

$$
\sigma=0.7326 \times F_{c}+340.12
$$

and in the case of clamping on the flange in the form:

$$
\sigma=0.1178 \times F_{c}+28.214 .
$$

\subsection{Lateral static stiffness}

The experiment input conditions remain the same as in the previous case. There is no other load on the circular saw blade besides the lateral force $F_{B}$, thus the model is statically analysed. Several combinations of parameters were selected to clarify the behaviour. The model is in this case the basic shape of the circular saw blade, which is loaded in two different points - with the tooth in the area of the outer expansion slot, other with the nearest tooth in the area of the inner slot. The results were compared for two different saw blade thicknesses of 2.6 and $3.0 \mathrm{~mm}$.

In Figure 9, the model was loaded with the lateral force $F_{B}$ as close as possible to the outer expansion slot. The maximum deformation is presented in the area of the applied force and is $0.35 \mathrm{~mm}$ in size. For this and other cases, the lateral force $F_{B}$ was $10 \mathrm{~N}$. Its magnitude is not decisive because the comparative stiffness values are given by the evaluation.

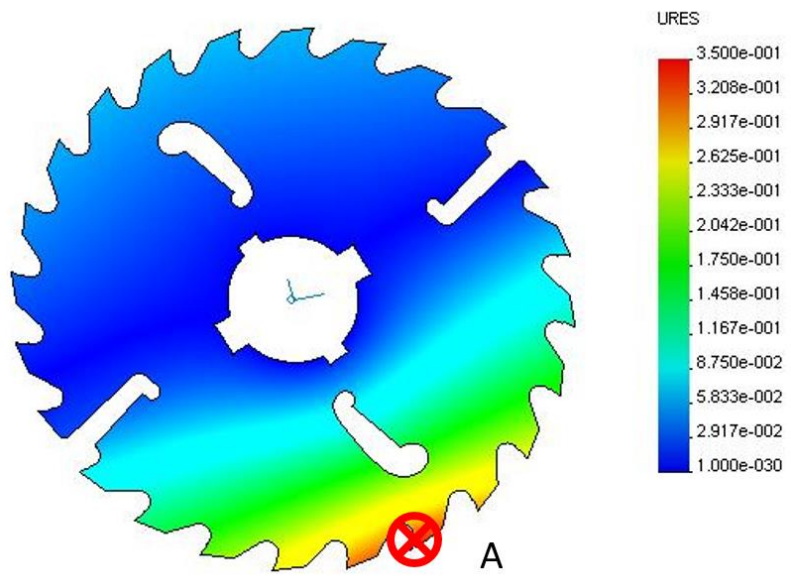

Fig. 9. Deformation response of circular saw blade loaded by lateral force in the marked point (A) for the body thickness of $2.6 \mathrm{~mm}$.

Figure 10 shows a deformation of the blade having a body thickness of $3.0 \mathrm{~mm}$. Thickness grew by $15.4 \%$ compared to the previous case. As expected, the circular saw blade has greater stiffness, which is because its deformation is smaller under the same conditions.

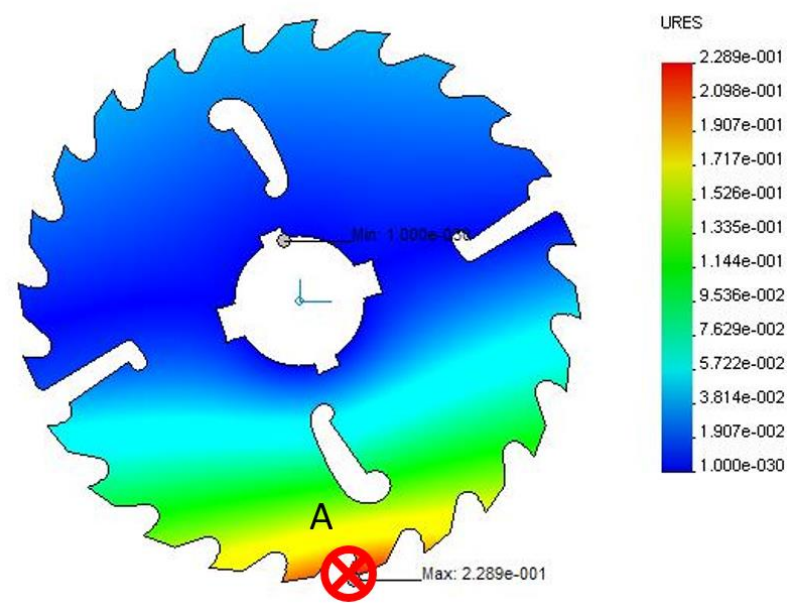

Fig. 10. Deformation response of circular saw blade loaded by lateral force in the marked point (A) for the body thickness of $3.0 \mathrm{~mm}$.

In Figures 11 and 12, the lateral force is placed in the circular saw blade attenuation at the outer expansion slot, marked as red cross (B). It is evident that the teeth of the saw blade itself is the most deformed and the size of the deformation reaches $0.4224 \mathrm{~mm}$ for a body thickness of $2.6 \mathrm{~mm}$ and $0.2753 \mathrm{~mm}$ for a circular saw blade with a body thickness of $3.0 \mathrm{~mm}$. However, the deformation response is not linear, and for both variants, deformation is $34.5 \%$ smaller. It can be stated that by increasing the saw blade thickness by $15.4 \%$, the stiffness of the circular saw blade increases by up to $53 \%$.

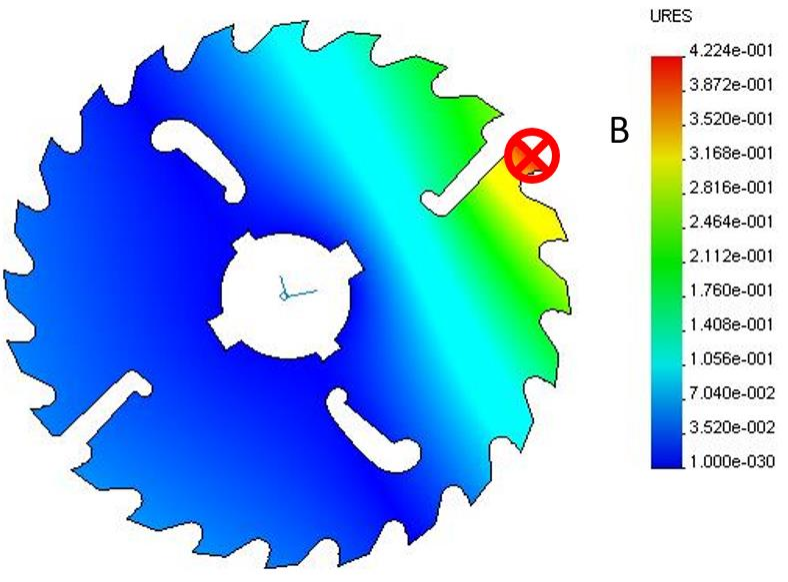

Fig. 11. Deformation response of circular saw blade loaded by lateral force in the marked point (B) for the body thickness of $2.6 \mathrm{~mm}$. 


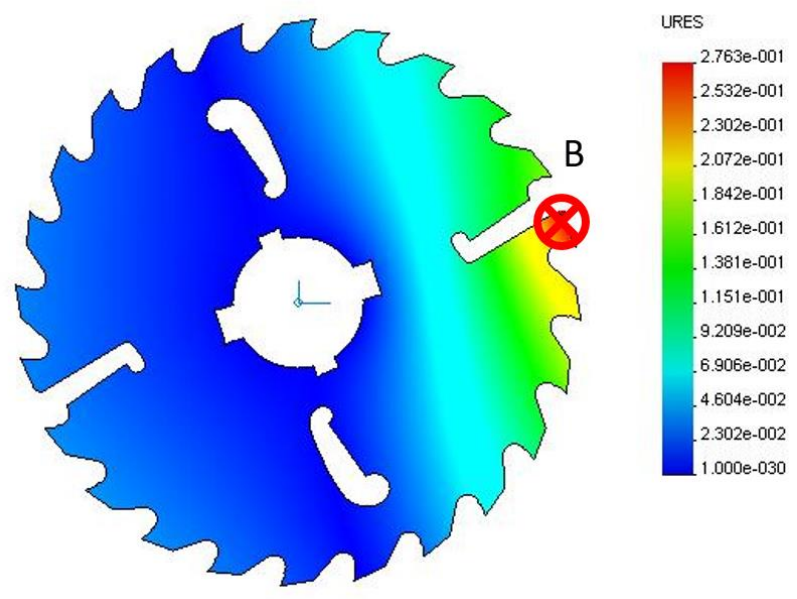

Fig. 12. Deformation response of circular saw blade loaded by lateral force in the marked point (B) for the body thickness of $3.0 \mathrm{~mm}$.

The resulting lateral stiffness values according to formula (1) are summarized in Table 4.

Table 4. Comparison of lateral stiffness of individual variants.

\begin{tabular}{|c|c|c|c|}
\hline $\begin{array}{c}\text { Circular saw } \\
\text { blade body } \\
\text { thickness }\end{array}$ & $\begin{array}{c}\text { Position } \\
\text { of lateral } \\
\text { force } F_{B}\end{array}$ & $\begin{array}{c}\text { Maximum } \\
\text { deflection } \\
y(\mathrm{~mm})\end{array}$ & $\begin{array}{c}\text { Lateral static } \\
\text { stiffness } C_{B} \\
(\mathrm{~N} / \mathrm{mm})\end{array}$ \\
\hline 2.6 & $\mathrm{~A}$ & 0.3500 & 28.57 \\
\hline 2.6 & B & 0.4224 & 23.67 \\
\hline 3.0 & A & 0.2289 & 43.69 \\
\hline 3.0 & $\mathrm{~B}$ & 0.2763 & 36.19 \\
\hline
\end{tabular}

\section{Conclusions}

Outputs show the possibility of identifying manufacturing, structural or operational defects in circular saw blades. Computer-based FEM models for behavioural modelling were used in this research. Mathematical interpretation of models $(2,3)$ predict the behaviour of von Mises' stress in dependence on the cutting force in the rotating circular saw blades. From presented experiments can be concluded that:

- the strength of the saw blade is significantly affected by the clamping quality.

- axis tilt of the circular saw blade has a significant impact on the loss of strength and can lead to critical states up to the tool breakage.

- the geometry of circular saw blade affects its strength. A weak spot between the outer slot and the key way may be a potential break point. It is recommended to produce a circular saw blade with the slots rotated by $45^{\circ}$.

- if the thickness of the body of circular saw blade increases by $15.4 \%$ (from 2.6 to $3.0 \mathrm{~mm}$ ), the blade stiffness increases by up to $53 \%$.

\section{References}

1. E. Šebelová, J. Chladil, Manuf. Technol. 13 (2013).

2. E. Csanády, E. Magoss, Mechanics of Wood Machining. (Springer, 2013).
3. A. Droba, J. Svoreň, J. Marienčík, Acta Univ. Agric. Silvic. Mendelianae Brun. 63 (2015).

4. K. Ukvalbergiene, J. Vobolis, Wood Res. 50 (2005).

5. V. T. Linh, Z. Yong, MATEC Web Conf. 51, 01007 (2016).

6. Y. M. Stakhiev, Holz als Roh- und Werkst. 61 (2003).

7. D. T. Oloruntoba, A. P. I. Popoola. Eng. Fail. Anal. 82 (2017).

8. A. Droba, L. Javorek, J. Svoreň, D. Paulíny. Drewno. 58 (2015).

9. J. Oravcová, P. Koštál, D. R. Delgado Sobrino, R. Holubek, Appl. Mech. Mater. 309 (2013).

10. J. Mackerle, J. Finite element analyses in wood research: a bibliography. Wood Sci. Technol. 39 (2005).

11. O. Bílek, M. Kovařík, Solid State Phenom. 261 (2017). 